\title{
SIMULASI KEKUATAN MONOCOQUE CHASSIS PADA MOBIL HEMAT ENERGI MENGGUNAKAN MATERIAL CARBON FIBER HONEYCOMB CORE
}

\author{
Milchan Aby Aufa*, Imam Syafaat dan Muhammad Dzulfikar \\ Jurusan Teknik Mesin, Fakultas Teknik, Universitas Wahid Hasyim \\ Jl. Menoreh Tengah X/22, Sampangan, Semarang 50236. \\ *Email: abyaufa22@gmail.com
}

\begin{abstract}
Abstrak
Kendaraan hemat energi adalah salah satu solusi menghemat persediaan sumber energi yang semakin menipis. Untuk pembuatan kendaraan hemat energi dapat dilakukan dengan modifikasi dengan mengurangi berat total bodi kendaraan dengan menggunakan chasis monocoque berbahan carbon fiber honeycomb core. Penelitian ini bertujuan untuk menganalisis pengaruh pembebanan pada variasi ketebalan carbon fiber honeycomb core terhadap distribusi tegangan dan deformasi pada prototype mobil hemat energi tim Aswaja Lintang Samudra dengan variasi ketebalan $10 \mathrm{~mm}, 9 \mathrm{~mm}$, dan $8 \mathrm{~mm}$ menunjukkan perbedaan pada chasis dengan beban yang sama yaitu beban pengemudi sebesar 610,03 $N$ dan beban engine sebesar 264,67 N. Dari penelitian ini dapat diketahui bahwa tegangan terbesar pada variasi ketebalan $8 \mathrm{~mm}$ diperoleh nilai tegangan sebesar 20,77 N/mm ${ }^{2}$, tegangan terendah pada variasi ketebalan $10 \mathrm{~mm}$ diperoleh nilai tegangan sebesar 16,52 N/mm $\mathrm{m}^{2}$. Sementara regangan terbesar pada variasi ketebalan $8 \mathrm{~mm}$ diperoleh nilai tegangan sebesar 0,13, tegangan terendah pada variasi ketebalan $10 \mathrm{~mm}$ diperoleh nilai regangan sebesar 0,09. Hasil safety factor menunjukkan gaya keseluruhan sebesar 882,7 N yang diberikan pada ketebalan $10 \mathrm{~mm}$ masih dibawah angka kekuatan luluh $\mathrm{Sy}=70 \mathrm{~N} / \mathrm{mm}^{2}$ bodi mobil mengalami deformasi elastis dapat kembali pada bentuk semula, menghasilkan nilai yaitu 4,237. Pada ketebalan $9 \mathrm{~mm}$ masih dibawah angka kekuatan luluh Sy $=58$ $\mathrm{N} / \mathrm{mm}^{2}$ bodi mobil mengalami deformasi elastis dapat kembali pada bentuk semula dan mendapatkan nilai yaitu 3,141. Pada ketebalan $8 \mathrm{~mm}$ masih dibawah angka kekuatan luluh $\mathrm{Sy}=14 \mathrm{~N} / \mathrm{mm}^{2}$ bodi mobil mengalami deformasi elastis dapat kembali pada bentuk semula dan mendapat nilai yaitu 0,674. Semua model dalam penelitian tersebut dapat dikatakan aman karena tegangan, regangan serta safety factor yang didapatkan dari hasil simulasi masih dibawah kekuatan material yang digunakan.
\end{abstract}

Kata kunci: carbon fiber, CFD, mobil hemat energi, monocoque chasis,

\section{PENDAHULUAN}

Chasis adalah struktur kendaraan yang membawa seluruh komponen dan membawa seluruh beban. Peranan chasis yaitu sebagai tempat terpasangnya komponen - komponen seperti suspensi, poros, body, pengereman, engine, dan komponen lainnya. Monocoque chassis adalah jenis chassis dimana Body kendaraan berfungsi sebagai Chassis, sehingga bentuknya sangat tergantung pada model dari kendaraan itu sendiri. Chassis Monocoque kekuatan utamanya terdapat pada lembaran lembaran baja atau komposit yang dijadikan satu atau diperkuat. Tujuan penggunaan bahan komposit pada chassis adalah memangkas berat kendaraan seringan mungkin tetapi tetap mempertahankan kekuatan dan keselamatan setara dengan logam.

\section{LANDASAN TEORI}

Resin komposit dapat didefinisikan sebagai gabungan dari dua atau lebih bahan yang berbeda sifat dan strukturnya yang bertujuan untuk menghasilkan sifat lebih baik yang tidak dapat didapatkan apabila bahan-bahan tersebut berdiri sendiri (Mc Cabe \& Walls, 2008). Komposit memberikan suatu pengertian yang sangat luas dan berbeda-beda, serta mengikuti situasi dan perkembangan bahan itu sendiri. Gabungan dua atau lebih bahan merupakan suatu konsep yang diperkenalkan untuk menerangkan definisi komposit.

Secara morfologi karbon fiber ada dalam berbagai bentuk, bubuk karbon aktif, pelumas padat karbon seperti gelas hitam yang sangat keras (Surdia dan Saito, 2000: 371). Jenis dan penggunaan karbon sangat luas dikarenakan sekarang sudah ada produksi masa dari serat karbon yang elastis dan dengan sifatnya yang ringan bahan ini memberikan harapan pada berbagai penggunaan. Karbon fiber adalah sebuah material komposit atau plastik diperkuat fiber yang sangat kuat, ringan, tetapi mahal. Plastik diperkuat gelas sering disebut fiber glass, material komposit umumnya ditunjukkan oleh nama serat penguatnya (karbon fiber). Bahan ini memiliki banyak aplikasi dalam konstruksi 
pesawat, otomotif, kapal layar, dan terutama banyak dipakai pada rangka sepeda modern, dimana kekuatan dan berat yang ringan sangat penting. Karbon fiber ditunjukkan pada Gambar 1 berikut ini:

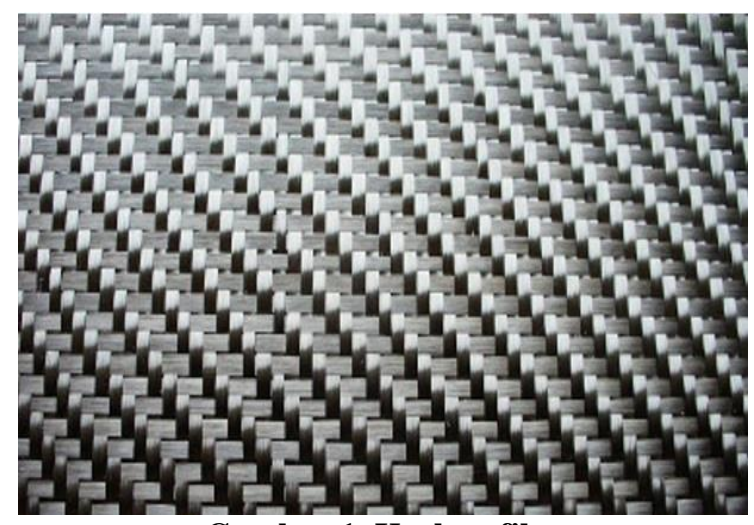

Gambar 1. Karbon fiber

Chassis pada kendaraan umumnya dipakai bahan logam baja atau Alumunium. Alasan digunakannya material baja adalah memiliki kekuatan yang tinggi serta pengerjaannya yang mudah dan alumunium karena tingkat kekuatan dan keuletannya sangat baik serta lebih ringan dari baja. Tetapi terdapat alternatif lain dengan mengganti kedua material tersebut dengan material komposit dikarenakan material komposit yang lebih ringan serta kuat.

Monocoque chassis adalah jenis chassis dimana Body kendaraan berfungsi sebagai Chassis, sehingga bentuknya sangat tergantung pada model dari kendaraan itu sendiri. Chassis Monocoque kekuatan utamanya terdapat pada lembaran - lembaran baja atau komposit yang dijadikan satu atau diperkuat. Tujuan penggunaan bahan komposit pada chassis adalah memangkas berat kendaraan seringan mungkin tetapi tetap mempertahankan kekuatan dan keselamatan setara dengan logam.

\section{METODE PENELITIAN}

\section{Alat dan Bahan}

Alat yang digunakan untuk penelitian adalah komputer pribadi. Penelitian ini menggunakan software metode simulasi pada struktur desain chassis dengan melakukan pengamatan dan menganalisis metode elemen hingga untuk mencari data sebab dan akibat oleh sesuatu pembebanan pada mobil hemat energi "Lintang Samudra" tipe prototipe milik tim Aswaja Unwahas yang dibuat dengan software Autodesk Inventor yang kemudian di ekspor untuk diubah format file ke IGESS (*igs) sebelum dan disimulasikan menggunakan software Solidworks untuk mendapatkan data hasil penelitian.

\section{Permodelan}

Untuk membuka aplikasi Solidworks 2014 dengan cara klik dua kali pada shortcut Solidworks 2014 yang sudah tersedia pada start menu. Kemudian akan ditampilkan layar pembuka Solidworks 2014 dan tampilan kerja secara berurutan akan diperlihatkan secara berurutan dengan melihat diagram alir pada Gambar 2.

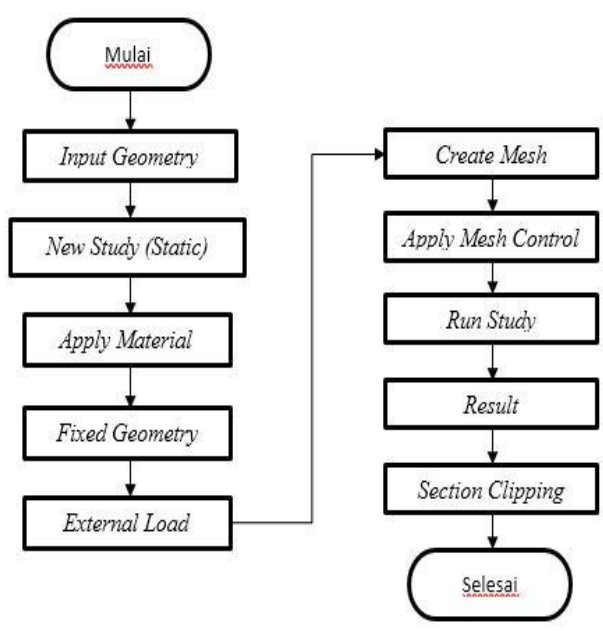

Gambar 2. Diagram alur simulasi

\section{HASIL DAN PEMBAHASAN \\ Hasil Tegangan}

Pada pengujian ini mendapatkan hasil simulasi tegangan yang terjadi pada desain body bawah tim Aswaja Lintang Samudra dengan variasi ketebalan $10 \mathrm{~mm}, 9 \mathrm{~mm}$, dan $8 \mathrm{~mm}$ ketika mendapat beban berat pengemudi dan berat engine.

Beban yang diberikan pada desain simulasi terbagi dua bagian yaitu bagian pengemudi dan engine. Pada bagian pengemudi mendapatkan beban sebesar $63 \mathrm{~kg}$ dan bagian engine mendapatkan beban sebesar $27 \mathrm{~kg}$. Kemudian dikonversikan menjadi Newton maka, beban pengemudi : $\mathrm{w}=63 \times 9,81=618,03$ $\mathrm{N}$ dan beban engine : $\mathrm{w}=27 \times 9,81=264,67 \mathrm{~N}$. Hasil tabel dan grafik tegangan pada ketebalan $10 \mathrm{~mm}, 9 \mathrm{~mm}$, dan $8 \mathrm{~mm}$ pada desain mobil Tim Aswaja.

a. Hasil tegangan pada desain bodi bawah mobil hemat energi Tim Aswaja Lintang Samudra dengan ketebalan $10 \mathrm{~mm}$ dijelaskan pada Gambar 3. 


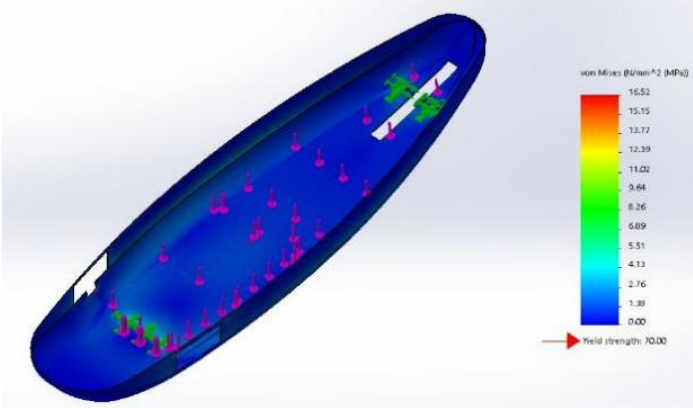

Gambar 3. Hasil tegangan bodi bawah dengan ketebalan $10 \mathrm{~mm}$

Hasil plot grafik dengan menggunakan pilihan section clipping, kemudian diarahkan pada dudukan baut roda depan yaitu pada titik fixed geometry dengan jarak dari ujung bodi belakang mobil $600 \mathrm{~mm}$. Lalu diberikan jumlah probe sebanyak 13 titik pada hasil potongan tersebut dan dijelaskan pada Gambar 4.

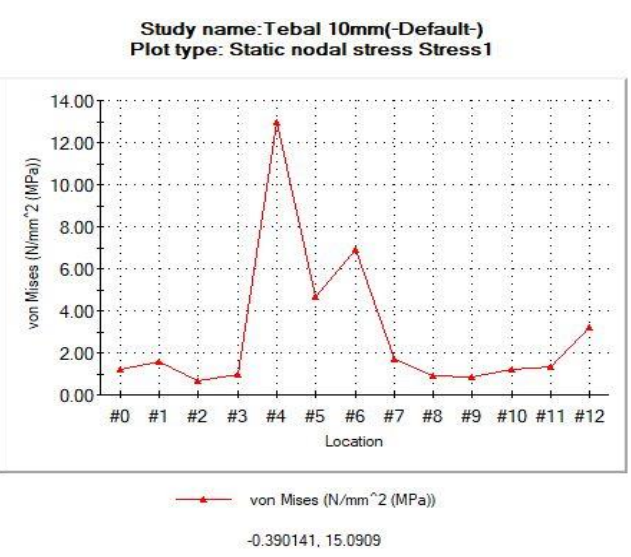

Gambar 4. Hasil plot grafik bodi bawah dengan ketebalan $10 \mathrm{~mm}$ pada fixed geometry bagian depan

Dari hasil plot grafik di atas dapat terbentuk seperti itu dikarenakan probe dibagi menjadi 13 bagian pada hasil potongan section clipping. Probe tersebut terdapat pada dudukan roda depan dan belakang yang mengalami titik tegangan maksimal dikarenakan posisinya sebagai fixed geometry (penampang beban) dan diperlihatkan pada Gambar 5.

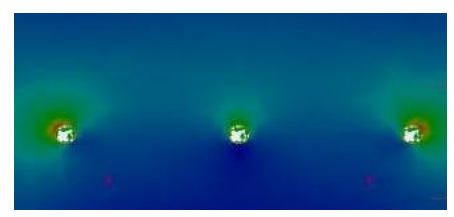

Gambar 5. Dudukan roda yang mengalami tegangan maksimal
Hasil plot grafik dengan menggunakan pilihan section clipping, kemudian diarahkan pada dudukan baut roda belakang yaitu pada titik fixed geometry dengan jarak dari ujung bodi belakang mobil $337,5 \mathrm{~mm}$. Lalu diberikan jumlah probe sebanyak 13 titik pada hasil potongan tersebut dan dijelaskan pada Gambar 6.

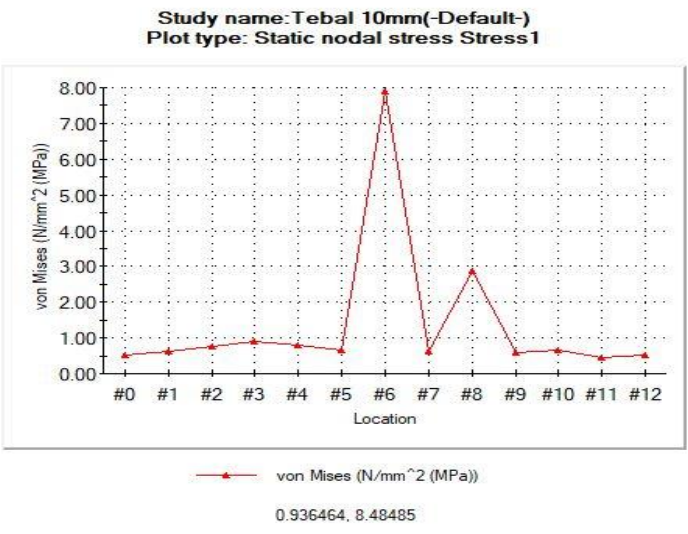

Gambar 6. Hasil plot grafik bodi bawah dengan ketebalan $10 \mathrm{~mm}$ pada fixed geometry bagian belakang

b. Hasil tegangan pada desain bodi bawah mobil hemat energi Tim Aswaja Lintang Samudra dengan ketebalan $9 \mathrm{~mm}$ dijelaskan pada Gambar 7.

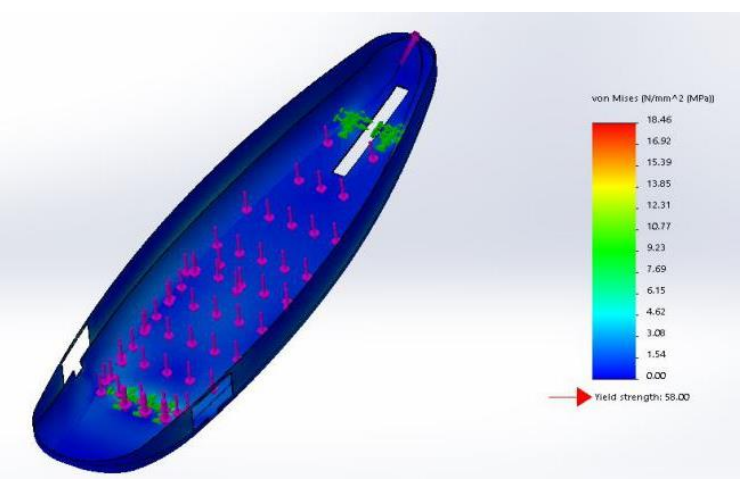

Gambar 7. Hasil tegangan bodi bawah dengan ketebalan 9 mm

Hasil plot grafik dengan menggunakan pilihan section clipping, kemudian diarahkan pada dudukan baut roda belakang yaitu pada titik fixed geometry dengan jarak dari ujung bodi depan mobil $600 \mathrm{~mm}$. Lalu diberikan jumlah probe sebanyak 13 titik pada hasil potongan tersebut dan dijelaskan pada Gambar 8 . 


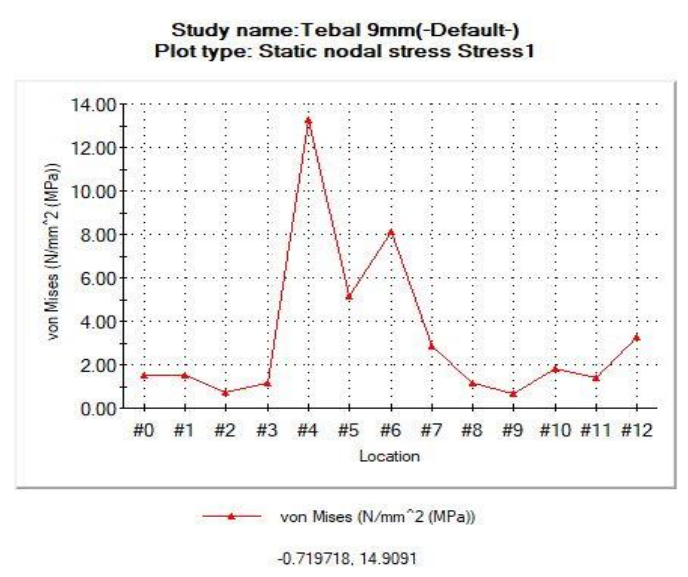

Gambar 8. Hasil plot grafik bodi bawah dengan ketebalan $9 \mathrm{~mm}$ pada fixed geometry bagian depan

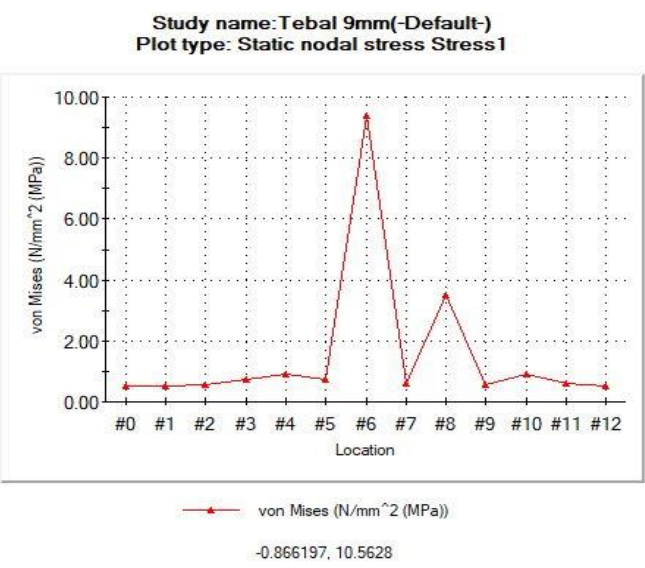

Gambar 10. Hasil plot grafik bodi bawah ketebalan $9 \mathrm{~mm}$, fixed geometry bagian belakang

Hasil plot grafik dengan menggunakan pilihan section clipping, kemudian diarahkan pada dudukan baut roda belakang pada titik fixed geometry dengan jarak dari ujung bodi belakang mobil 337,5 mm. Lalu diberikan jumlah probe sebanyak 13 titik pada hasil potongan tersebut dan dijelaskan pada Gambar 10.
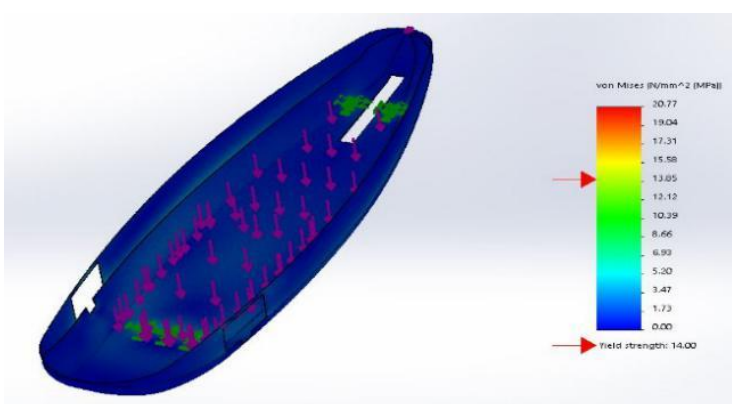

Gambar 11. Hasil tegangan bodi bawah dengan ketebalan 8 mm

c. Hasil tegangan pada desain bodi bawah mobil hemat energi Tim Aswaja Lintang
Samudra dengan ketebalan $8 \mathrm{~mm}$ dijelaskan pada Gambar 11.

Hasil plot grafik dengan menggunakan pilihan section clipping, kemudian diarahkan pada dudukan baut roda belakang yaitu pada titik fixed geometry dengan jarak dari ujung bodi depan mobil $600 \mathrm{~mm}$. Lalu diberikan jumlah probe sebanyak 13 titik pada hasil potongan tersebut dan dijelaskan pada Gambar 12.

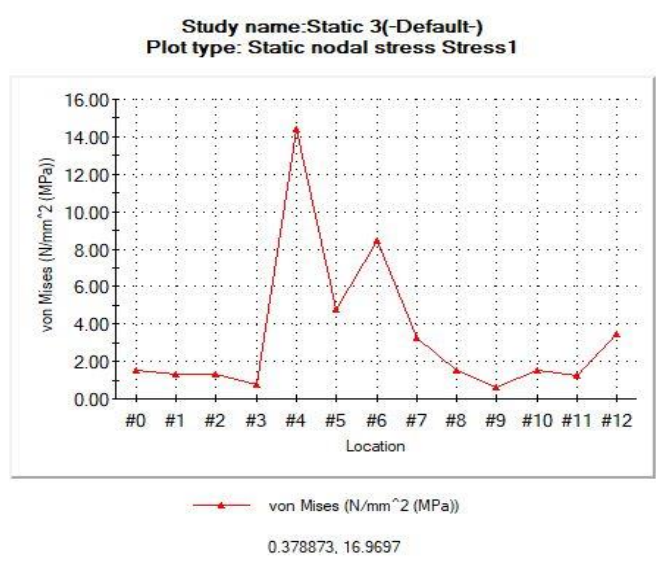

Gambar 12. Hasil plot grafik bodi bawah dengan ketebalan $8 \mathrm{~mm}$ pada fixed geometry bagian depan

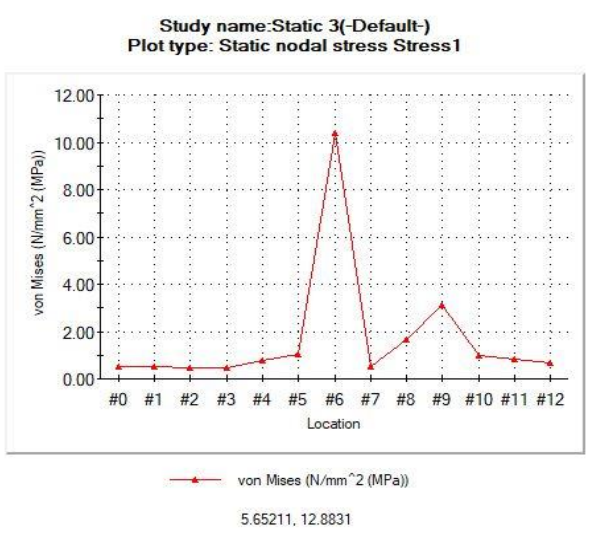

Gambar 13. Hasil plot grafik bodi bawah ketebalan $8 \mathrm{~mm}$ pada fixed geometry bagian belakang

Tabel 1 Hasil Tegangan

\begin{tabular}{lll}
\hline No. & Ketebalan & Tegangan \\
\hline 1 & $10 \mathrm{~mm}$ & $16,52 \mathrm{~N} / \mathrm{mm}^{2}$ \\
2 & $9 \mathrm{~mm}$ & $18,46 \mathrm{~N} / \mathrm{mm}^{2}$ \\
3 & $8 \mathrm{~mm}$ & $20,77 \mathrm{~N} / \mathrm{mm}^{2}$ \\
\hline
\end{tabular}

Hasil plot grafik dengan menggunakan pilihan section clipping, kemudian diarahkan pada dudukan baut roda belakang yaitu pada titik 
fixed geometry dengan jarak dari ujung bodi belakang mobil 337,5 mm. Lalu diberikan jumlah probe sebanyak 13 titik pada hasil potongan tersebut dan dijelaskan pada Gambar 13.

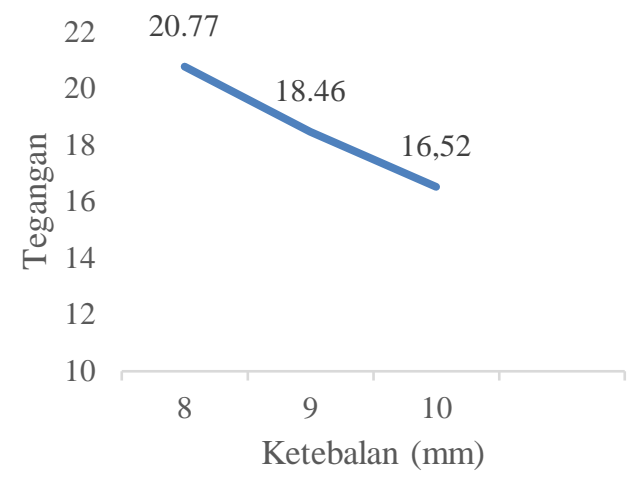

Gambar 14. Grafik tegangan pada desain mobil Tim Aswaja Lintang Samudra

\section{Hasil Regangan}

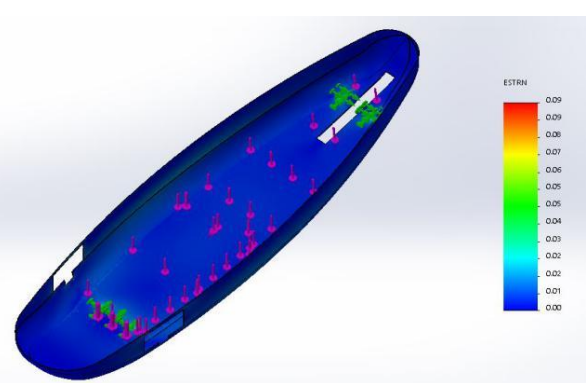

Gambar 14. Hasil regangan bodi bawah dengan ketebalan $10 \mathrm{~mm}$

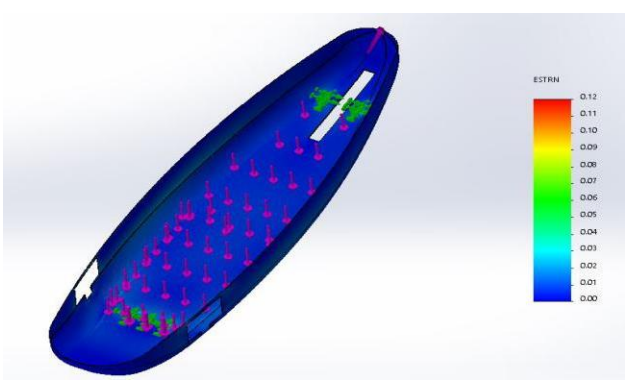

Gambar 15. Hasil regangan bodi bawah dengan ketebalan 9 mm

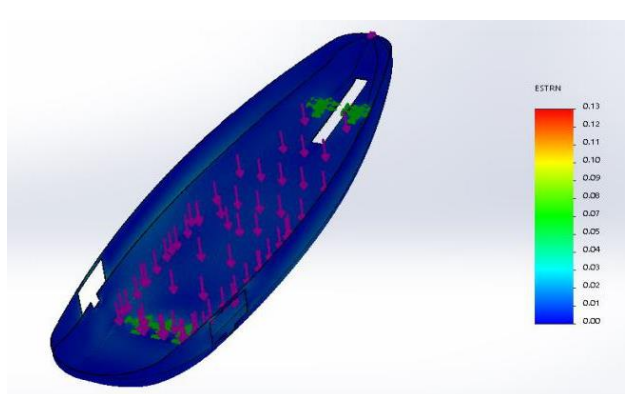

Gambar 16. Hasil regangan bodi bawah dengan ketebalan 8 mm
Hasil tabel dan grafik regangan pada ketebalan $10 \mathrm{~mm}, 9 \mathrm{~mm}$, dan $8 \mathrm{~mm}$ pada desain mobil Tim Aswaja

a. Hasil regangan pada desain bodi bawah mobil hemat energi Tim Aswaja Lintang Samudra dengan ketebalan $10 \mathrm{~mm}$

b. Hasil regangan pada desain bodi bawah mobil hemat energi Tim Aswaja Lintang Samudra dengan ketebalan $9 \mathrm{~mm}$

c. Hasil regangan pada desain bodi bawah mobil hemat energi Tim Aswaja Lintang Samudra dengan ketebalan $8 \mathrm{~mm}$

\begin{tabular}{lll}
\multicolumn{3}{l}{ Tabel 2 Hasil Regangan } \\
\hline No & Ketebalan & Regangan \\
\hline 1 & $10 \mathrm{~mm}$ & 0,09 \\
2 & $9 \mathrm{~mm}$ & 0,12 \\
3 & $8 \mathrm{~mm}$ & 0,13 \\
\hline
\end{tabular}

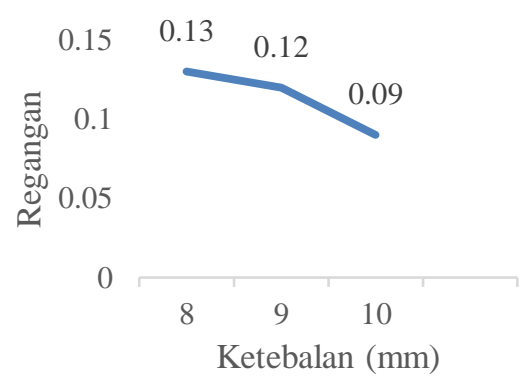

Gambar 16. Grafik regangan pada desain mobil Tim Aswaja Lintang Samudra

\section{Perhitungan Faktor Keamanan}

Dari hasil simulasi pembebanan pada desain mobil Tim Aswaja Lintang Samudra dengan variasi ketebalan $10 \mathrm{~mm}, 9 \mathrm{~mm}$, dan $8 \mathrm{~mm}$ dengan beban yang sama yaitu beban pengemudi sebesar 610,03 $\mathrm{N}$ dan beban engine sebesar 264,67 N, maka pembebanan keseluruhan sebesar 882,7 $\mathrm{N}$ akan dapat menentukan tegangan maksimal yang terjadi yaitu:

\section{a. Ketebalan $10 \mathrm{~mm}$}

Dengan gaya keseluruhan sebesar 882,7 $\mathrm{N}$ yang diberikan pada desain mobil adalah $16,52 \mathrm{~N} / \mathrm{mm}^{2}$ masih dibawah angka kekuatan luluh $S y=70 \mathrm{~N} / \mathrm{mm}^{2}$ bodi mobil masih mengalami deformasi elastis dimana bodi mobil dapat kembali pada bentuk semula.

Perhitungan manual safety factor menggunakan rumus sebagai berikut:

Sf $\quad=\frac{s y}{\sigma}=\frac{70}{16,52}=4,237$ 
Nilai faktor keamanan pada pengujian desain mobil Tim Aswaja Lintang Samudra dengan ketebalan $10 \mathrm{~mm}$ yaitu 4,237

\section{b. Ketebalan $9 \mathrm{~mm}$}

Dengan gaya keseluruhan sebesar 882,7 $\mathrm{N}$ yang diberikan pada desain mobil adalah $18,46 \mathrm{~N} / \mathrm{mm}^{2}$ masih dibawah angka kekuatan luluh $S y=58 \mathrm{~N} / \mathrm{mm}^{2}$ bodi mobil masih mengalami deformasi elastis dimana bodi mobil dapat kembali pada bentuk semula.

$$
S f \quad=\frac{s y}{\sigma}=\frac{58}{18,46}=3,141
$$

Nilai faktor keamanan pada pengujian desain mobil Tim Aswaja Lintang Samudra dengan ketebalan $9 \mathrm{~mm}$ yaitu 3,141

\section{c. Ketebalan $8 \mathrm{~mm}$}

Dengan gaya keseluruhan sebesar 882,7 N yang diberikan pada desain mobil adalah 20,77 $\mathrm{N} / \mathrm{mm}^{2}$ masih dibawah angka kekuatan luluh $S y$ $=14 \mathrm{~N} / \mathrm{mm}^{2}$ bodi mobil masih mengalami deformasi elastis dimana bodi mobil dapat kembali pada bentuk semula.

$$
\text { Sf } \quad=\frac{s y}{\sigma}=\frac{14}{20,77}=0,674
$$

Nilai faktor keamanan pada pengujian desain mobil Tim Aswaja Lintang Samudra dengan ketebalan $8 \mathrm{~mm}$ yaitu 0,674

\section{KESIMPULAN}

Dari hasil simulasi pada bodi mobil Tim Aswaja Lintang Samudra dapat disimpulkan bahwa :
a. tebal $10 \mathrm{~mm}$ : tegangan $16,52 \mathrm{~N} / \mathrm{mm}^{2}$, regangan 0,09
b. tebal $9 \mathrm{~mm}$ : tegangan $18,46 \mathrm{~N} / \mathrm{mm}^{2}$, regangan 0,12
c. tebal $8 \mathrm{~mm}$ : tegangan $20,77 \mathrm{~N} / \mathrm{mm}^{2}$, regangan 0,13

Faktor keamanan pada bodi mobil Tim Aswaja Lintang Samudra hasil tegangan masih di bawah dari kekuatan luluh (yield strength) dengan material yang digunakan yaitu 4,237 pada ketebalan $10 \mathrm{~mm}, 3,141$ pada ketebalan $9 \mathrm{~mm}$, dan 0,674 pada ketebalan $8 \mathrm{~mm}$.

\section{SARAN}

Menentukan material untuk spesimen yang akan digunakan pada bodi mobil yang akan dibuat. Mencari data dengan teliti untuk menghasilkan data yang akurat. Mempelajari proses simulasi dengan menggunakan aplikasi Solidworks 2014. Mengetahui spesifikasi laptop/PC supaya proses simulasi berjalan lancar dan tidak terjadi error

\section{DAFTAR PUSTAKA}

Mc Cabe JF WallsA, 2008, Aplied dental Materials, $9^{\text {th }}$ ed. Singapore: Blackwell Publishing.

Surdia, Tata. Saito., 2000, Pengetahuan Bahan Teknik. Pradnya Paramita. Jakarta 